We previously reported another difficulty with the Boyle Model 10 gas machine, in which oxygen leaked into the nitrous oxide supply through a defective oxygen fail-safe device. ${ }^{1}$ We recommend that both problems should be corrected, in the interest of patient safety.

\author{
JOHN LONGMUIR AND \\ Douglas B. Craig, M.D. \\ Department of Anesthesia, \\ Health Sciences Centre, \\ University of Manitoba, \\ Winnipeg, Manitoba.
}

REFERENCE

1. Craig, D.B. \& Longmuir, J. An Unusual Failure of an Oxygen Fail-Safe Device. Can. Anaes. Soc. J. 18: 576-577 (1971).

Sir:

\title{
Bain Circuit
}

In his article ("Spontaneous ventilation with the Bain circuit at low flow rates: a case report" C.A.S.J. 23/4; 432, 1976) Dr. Mansell recommends that patients anaesthetized in this fashion should have their respirations augmented or controlled. While subscribing to this warning, I would like to comment on other aspects of the paper.

The author draws the right conclusion from the wrong premises. I submit that his data reflect the overall responsiveness of his patient at various moments during anaesthesia rather than the efficiency of the two breathing circuits studied by him. This responsiveness was relatively low during the first observational period as would be expected and then stabilized for the remainder of the procedure. I venture to predict that the same blood-gas data would have been obtained from this spontaneously ventilating subject had the fresh gas flow been doubled or had there been $\mathrm{COO}_{2}$ absorber added to the breathing circuit.

The Magill-circuit may be rebreathing or non-rebreathing depending on the rate of fresh-gas inflow. There is no argument that the configuration of the Bain circuit is less efficient and that at the recommended fresh gas inflow rate, rebreathing is likely to occur. The question is, what practical problems can be expected from this situation?

To the extent that at the end of each respiratory cycle the anatomical dead-space is filled with alveolar gases, some rebreathing will occur at all times. Increased admixture of exhaled gases is of concern mainly because it reduces the effectiveness of gas exchange and, for this reason, increases the work of respiration associated with a given level of $\mathrm{CO}_{2}$ production. Should this work be assumed by another mechanism, the anaesthetist's hand or a ventilator, the situation becomes much more tolerable and possible advantages should be weighed before any effort is expended to eliminate it. Rebreathing is not a dirty word per se: under suitable circumstances it can work in the patient's (and thus in the anaesthetist's) favour. 
$1 /$ Only with rebreathing is it possible to combine vigorous expansion of the lungs during anaesthesia with normal $\mathrm{CO}_{2}$ homeostasis. This results in an appreciable reduction of shunting across the lungs during surgery. ${ }^{1}$ The degree of improvement is such that one-lung anaesthesia with 70 per cent nitrous oxide will provide normal arterial oxygen tensions as long as the dependent lung is healthy.

2 / Only by rebreathing is it possible to selectively regulate $\mathrm{CO}_{2}$ tension without changing other respiratory parameters. This has been utilized in neurosurgery, neuro-radiology and carotid artery surgery but it can also be applied to other fields of anaesthesia, e.g. for providing exceptionally smooth and precisely timed return of consciousness. This writer reduces the fresh gas in-flow from 31 per sq. metre per minute (a figure applicable to a wider population than the original suggestion of $70 \mathrm{ml}$ per $\mathrm{kg}$ per minute) to 11 towards the end of the procedure, say at the start of, or midway through skin closure, without changing any of the respirator settings. This will result in $\mathrm{CO}_{2}$ retention at the rate of about 2 torr per minute and if the patient is not curarized or if curarization has been reversed, spontaneous ventilatory efforts should become visible within five minutes. At this moment the ventilator is turned off and the gas-flow is returned to its original level. The patient is disconnected from the apparatus as the dressings are applied and is expected to extubate himself before he leaves the operating theatre.

3 / Rebreathing solves the problem of heating anaesthetic gases without the need for additional equipment. The exhaled gases in the Bain circuit warm the central tube conducting fresh gases to the patient. The counter-current distribution of thermal gradients makes this procedure particularly efficient. The same process conserves much of the humidity of the rebreathed gas fraction, contributing at least a partial solution to this problem too.

4/ The placement of the overflow valve and a RMV well in excess of the freshgas inflow combine to smooth out at the valve the conventional peak and valley of $\mathrm{CO}_{2}$ concentrations in the course of a respiratory cycle. This in turn makes it possible to monitor the subject's $\mathrm{CO}_{2}$ output more accurately than has been the case before. ${ }^{2}$ Commercially available $\mathrm{CO}_{2}$ analyzers clearly indicate a 5 per cent difference in this parameter and a 10 per cent difference is unmistakable. Sudden increases of this magnitude precede other signs of lightening anaesthesia by several minutes. Comparable drops suggest an interference with $\mathrm{CO}_{2}$ transfer from the tissues to the lungs. This phenomenon has been utilized to test the limits to which planned hypotension may be pushed in subjects with compromised cardiovascular status. ${ }^{3}$ One of the problems in introducing the Bain circuit to audiences, visitors and new residents is that the terminology needs to be carefully defined. Ventilation (i.e. movement of gases in and out of the lungs) will be the limiting factor in $\mathrm{CO}_{2}$ elimination as long as it is low in comparison to the volume of fresh gases entering the circuit. As it exceeds this figure, however, the fresh gas inflow takes over as the rate-limiting step: true alveolar ventilation cannot be greater than the fresh gas inflow. It is in this range of ventilation that the full benefits of the system become apparent and therefore it is in this range that it will be used to best advantage.

Michael Keeri-Szanto, M.D.

Victoria Hospital, London, Ontario, N6A 4G5. 


\section{REFERENCES}

1. Knill, R. Venous admixture during anaesthesia with positive pressure ventilation: the effect of rebreathing, C.A.S. Congress, Montreal, 1976.

2. Keeri-Szanto, M. Thermal shifts during major surgery. C.A.S. Congress, Kingston, 1975.

3. Keeri-Szanto, M. Extending the indications for planned hypotension. C.A.S. Congress, Montreal, 1976.

\section{Dear SIR:}

I agree completely with Dr. W. H. Mansell's conclusions in the article on the Bain Circuit (C.A.S.J. 23: 432 (1976)).

For controlled ventilation the Bain Circuit is excellent, with predictable $\mathrm{Pa}_{\mathrm{CO}_{2}}$ values within an acceptable range at varying fresh gas inflow rates. ${ }^{1}$ The values are similar to those produced at the same inflow rates, under controlled ventilation, with the modified Ayre's T-piece."

I found that in 22 patients, using the Bain Circuit with spontaneous ventilation, much higher fresh gas inflow rates were required to approach an acceptable $\mathrm{Pa}_{\mathrm{CO}_{2}}$. In two groups of 11 patients each, using the Bain Circuit with flow rates of $100 \mathrm{ml} / \mathrm{kg}$ and $130 \mathrm{ml} / \mathrm{kg}$ respectively, with spontaneous ventilation, $\mathrm{N}_{2} \mathrm{O}$ 66 per cent, Halothane $<0.75$ per cent, the average $\mathrm{Pa}_{\mathrm{CO}_{2}}$ at the end of 30-50 minutes was 48.9 torr and 45.6 torr respectively. The $\mathrm{PaCo}_{2}$ varied from 36.2 torr to a disturbingly high 63.2 torr!

In contrast, using a circle system with $\mathrm{CO}_{2}$ soda-lime absorber, spontaneous ventilation, a gas-conserving $\mathrm{N}_{2} \mathrm{O}-\mathrm{O}_{2}$ inflow of 2 and $11 / \mathrm{min}$, and Halothane $<1.0$ per cent, the average $\mathrm{Pa}_{\mathrm{CO}_{2}}$ at the end of $30-90$ minutes was 31.1 torr. No $\mathrm{Pa}_{\mathrm{CO}_{2}}$ was higher than 42 torr.

The groups studied were comparable for age range, weight, type of surgery, and were all ASA status 1.

It is apparent that the Bain Circuit is most useful and efficient for certain procedures, using controlled ventilation. For those adult patients who are to be managed with spontaneous ventilation, there are better anaesthetic systems.

Kenneth Goodwin, M.D.

Ottawa, Ontario.

1. BAin, J.A. \& Spoenel, W.E. Prediction of arterial carbon dioxide tension during controlled ventilation with a modified Mapleson D system. C.A.S.J. 22: 34 (1975).

2. Coonwin, K.M. Unpublished data. 